\title{
LA ATENCIÓN DE MANUEL REVUELTA AL PATRIMONIO ARTÍSTICO DE SU PALENCIA NATAL
}

\author{
RICARDO PINILLA BURGOS ${ }^{1}$
}

RESUMEN: Destacamos una faceta de la labor ingente del Manuel Revuelta que aúna el amor a su tierra natal y su mirada experta de historiador, abordando su atención de los avatares de la conciencia artística en la provincia de Palencia, desarrollada especialmente en un estudio aparecido en 1999. Revuelta parte de una interesante noción de "conciencia artística», que implica no sólo la conservación y cuidado sino la valoración y estudio del patrimonio de una región, con sus implicaciones culturales y religiosas. El recorrido que nos propone centrado en Palencia y el conocimiento de sus tesoros artísticos es a la vez un análisis muy sugerente de la misma historia de España entre el siglo XVIII y los inicios del XX, y cómo se jugaron las relaciones entre la Iglesia, el estado, las nuevas ideas políticas y el valor espiritual y cultural del arte.

PaLABRAS ClaVE: Conciencia artística; Palencia; desamortización; patrimonio artístico; arte religioso.

\section{Manuel Revuelta's attention to the artistic heritage of his native Palencia}

ABSTRACT: We highlight a facet of the enormous work of Manuel Revuelta that combines the love for his native land and his expert gaze as a historian, addressing his attention to the vicissitudes of artistic consciousness in the province of Palencia, developed especially in a study that appeared in 1999. Revuelta starts from an interesting notion of "artistic consciousness", which implies not only the conservation and care but also the valuation and study of the heritage of a region, with its cultural and religious implications. The tour he proposes focusing on Palencia and the knowledge of its artistic treasures is both a very suggestive analysis of the history of Spain between the eighteenth century and the beginning of the twentieth, and of the relevance of the relations between the church, the state, new political ideas and the spiritual and cultural value of art.

KEY WORDS: Artistic consciousness; Palencia; ecclesiastical confiscation; artistic heritage; religious art.

1 Director del Departamento de Filosofía y Humanidades. Universidad Pontificia Comillas. Correo electrónico: pinilla@comillas.edu. 


\section{RAÍZ Y APERTURA: LA PREOCUPACIÓN DE REVUELTA POR EL LEGADO ARTÍSTICO DE SU TIERRA NATAL}

«Yo soy de los que piensan, y para mí es muy importante, que los hombres somos de algún sitio. Lo ideal es que seamos de un lugar, que tengamos las raíces en un lugar, pero que nuestros brazos lleguen a todo el mundo, que nos valgan las ideas de cualquier cultura». Estas palabras del escultor vasco y universal Eduardo Chillida se podrían aplicar muy bien a la obra y el talante de Manuel Revuelta. Su amplia labor como gran especialista en el siglo XIX, e insigne historiador de la Compañía de Jesús, no le llevó a olvidar su paisanaje castellano, y muy especialmente su querida Palencia natal. El tributo a su querido arraigo lo realizó Revuelta haciendo lo que mejor hacía: estudiando con atención y rigor el legado histórico y cultural de su tierra. En efecto, en su extensísima bibliografía encontramos hasta una docena de trabajos dedicados a diversos aspectos históricos, religiosos y culturales relativos a la provincia palentina. Contribuyó entre otros trabajos a la Historia de Palencia: siglos XIX y XX, coordinada por Pablo García Colmenarejo, J. Moreno Lázaro y J. Sánchez García (Revuelta, 1996) y fue uno de los principales ponentes en los tres congresos de Historia de Palencia $(1985,1989,1995)$.

De entre esos abundantes y prolijos trabajos nos fijaremos en su artículo «Recuperación de la conciencia artística de Palencia», aparecido en 1999 en las Publicaciones de la Institución Tello Téllez de Meneses, actualmente también Academia Palentina de Historia, Letras y Bellas Artes, en la que nuestro historiador ingresaba como miembro el 4 de mayo de 1992.

La conciencia artística es considerada por Revuelta como el aprecio y el cuidado que en cada época se tuvo de este patrimonio, esto es, la consciencia de su valor, que implica un estudio y comprensión del mismo, y de otro lado, una conservación: "Conciencia artística es la estima consciente hacia las obras de arte. Se posee consciencia histórica y artística cuando se conocen y valoran los legados del pasado, como tesoros que merecen ser debidamente entendidos y celosamente conservados» (Revuelta, 1999, p. 359). Se añade así a esta conciencia la dimensión de la conciencia histórica que nos permite valorar en su justa medida cada obra, su contexto y su significado cultural y religioso. El artículo nos brinda un recorrido por las diversas etapas históricas de la España más reciente, desde el siglo XVIII hasta inicio del XX, atendiendo a la percepción y valoración que se fue teniendo del sin duda valioso legado y patrimonio artístico palentino. Esta acotación nos lleva a un periodo en el que Revuelta se alza como una de las voces y miradas más expertas de la historiografía de España. Es en ese periodo donde quiere centrarse nuestro 
autor, por ser el «más crítico», esto es, donde tendrá lugar la progresiva pérdida y deterioro de la conciencia artística y su ulterior recuperación.

El término «recuperación» en el título de este escrito ya nos avisa así de que esa conciencia no siempre habrá existido, o incluso se llegó a perder, con consecuencias no sólo de olvido, sino de grave destrucción y expolio del patrimonio. Revuelta llega a hablar de «incuria» en este sentido. Incuria que ha de denunciarse respecto al legado general artístico en España. En esto, Palencia, como nos recuerda Revuelta, «no fue una excepción», si bien habría que añadir el hecho de no ser el palentino un legado tan popularmente conocido como el de otras provincias españolas, y aun dentro de Castilla. $\mathrm{Al}$ no caer en rutas y caminos tan centrales a lo largo de la historia, como Burgos, Valladolid o León, indica Revuelta que durante el siglo XIX Palencia "seguía siendo la gran desconocida de los libros de Geografía» (p. 367). Con excepción de la «grande y bella catedral», los tesoros artísticos palentinos, se podría decir que sufrirán un doble olvido: el achacable a la ausencia general de conciencia artística patria y el que es consecuencia de no ser Palencia una de las provincias principales de Castilla. En este sentido el trabajo históricoartístico del investigador podría aún en nuestros días tener una carga reivindicativa mayor que el referente a otras partes de nuestro legado artístico, y hemos de agradecer a estudiosos como Revuelta que acometieran el estudio de rigor, a la vez que cercano, de cuestiones como las que ahora nos ocupa.

\section{LA HERENCIA INTACTA Y EL COMIENZO DE LA CONCIENCIA ARTÍSTICA ILUSTRADA: LAS CRÓNICAS PALENTINAS DE ANTONIO PONZ Y JOVELLANOS}

Se inicia en el citado estudio la andadura histórica a finales del Antiguo Régimen, en las últimas décadas del siglo XVIII. Revuelta nos indica algo valioso y no siempre tenido en cuenta: que el rico patrimonio artístico de las numerosas iglesias y conventos en España, y también en Palencia, «llegó a finales del siglo XVIII con una riqueza artística completa» (p. 360). La vida religiosa se mantenía activa en los más de 3.000 conventos repartidos por toda la geografía española, y en las ciudades y cada pueblo las parroquias recibían suficientes recursos económicos para su cuidado y conservación. Revuelta no se refiere expresamente a la arquitectura civil y militar; la primera quizá más escasa en comparación con la grandeza y abundancia de la religiosa, y la segunda acaso en parte derruida o en parte también reformada para su posterior uso militar. Hasta este momento esta riqueza del patrimonio 
artístico, nos indica Revuelta «se poseía, no se cuestionaba. No se discutía como problema, pues era tan natural como el paisaje» (p. 360). Podemos así ver que hasta esa época habría una ausencia de conciencia general de una necesidad de cuidar o conservar un patrimonio que en su riqueza y abundancia poblaba la geografía casi como los elementos naturales del entorno.

Será con la Ilustración cuando comienza a haber descripciones y estudios sistemáticos del patrimonio y relatos ocasionados por viajes. Revuelta menciona ilustres excepciones como toda la labor y obra arqueológica de Ambrosio de Morales (1513-1591), pero son los trabajos y las descripciones de viaje de Antonio Ponz (1725-1792) los que tuvieron una amplia divulgación. Estos trabajos presentaban un criterio sistemático, no eran simples inventarios de datos aislados, y se puede decir que en este sentido eran acordes con la naciente ciencia y conciencia historiográfica en torno al patrimonio y los vestigios históricos y artísticos. Ponz además sí se ocupó expresamente la provincia de Palencia; y también alude Revuelta en este sentido a los valiosos diarios de Jovellanos, que sin embargo permanecieron inéditos hasta principios del siglo XX. De estos trabajos Revuelta deduce que hasta finales del XVIII el patrimonio artístico palentino se conservaba completo e intacto. En lo referente a los criterios y conciencia artística de estos autores, habría que destacar, en primer lugar, su método de observación directa, pues ambos hicieron viajes por toda la provincia palentina (Ponz en 1783 y Jovellanos en 1791 y 1795). Revuelta nos hace ver también que los criterios de valoración de ambos no son ecuánimes, quedando muy presentes sus preferencias y opciones estilísticas, que se inclinan en ambos casos por el arte renacentista y plateresco y mantienen un desprecio casi visceral del barroco. Hasta ahí esto era acorde con el gusto neoclásico de la época, pero no deja de acusar nuestro historiador la poca valoración de las joyas de arquitectura románica y gótica presentes en diversas localidades palentinas. Con independencia de la valoración o crítica frontal de estas lagunas, estimo que este sesgo, de un lado, nos permite ver lo mucho que posteriormente el periodo romántico y todo el siglo XIX influirá en nuestra valoración de las iglesias y claustros medievales (los góticos y también los románicos) y de otro, que en este periodo de surgimiento de la conciencia artística no existía seguramente una apreciación objetiva de todo el patrimonio artístico sin excepción, como la conciencia artística y estética modernas llegarán a realizar llevando este proceso a una cierta visión de "simultaneidad» del valor de toda obra de arte, por el hecho de serlo y de ser un legado del pasado, en el sentido que apuntó el filósofo Hans-Georg Gadamer (Gadamer, 1984, p. 126). Si vemos estas lagunas o parcialidades desde el punto de vista de la crítica gadameriana a la conciencia estética, podríamos decir que en las opciones de Ponz y 
Jovellanos encontraríamos una mayor implicación directa y vital con la apreciación de los diferentes estilos y la verdad que pueden transmitir; aunque sin duda, antes de apelar a esa actitud ante el patrimonio parecía necesario un estudio amplio y una valoración más objetiva y completa del mismo. Esto aún se hará más necesario conforme avance el siglo XIX con sus numerosos avatares sociales y políticos que pondrán en gran peligro la misma integridad y conservación del patrimonio artístico español y por ende también el de la provincia de Palencia.

De las descripciones de Ponz y Jovellanos, Revuelta reconstruye una ciudad de Palencia aún rodeada de murallas y con bellas arboledas, nos indica cómo existen numerosos conventos en los que se han ido acumulando diversas obras y tesoros artísticos, desde pinturas hasta vasos sagrados y ropas; y dando datos sobre la riqueza y buen estado de conservación de lugares como el claustro de San Zoilo, en Carrión, donde dan cuenta estos viajeros de otras iglesias, como también en localidades como Becerril o Paredes de Nava. Revuelta advierte, a pesar de esas críticas a su parcialidad en la valoración de diferentes estilos o su desprecio del arte medieval, que estos ilustrados "podrían ser partidarios de la desamortización, pero estimaban la herencia artística y monumental que les rodeaba» (Revuelta, 1999, p. 362). Esta puntualización es muy importante a la vista de lo que sucederá después, en el que las ideas de progreso político y de crítica al poder casi aún estamental de la Iglesia de la España decimonónica implicarán un dañino e injusto desprecio y descuido del patrimonio artístico, que en su mayor parte tenía una procedencia religiosa.

El ambiente ilustrado permite en general en España la promoción de publicaciones, instituciones y museos que sentarán la base de la moderna conciencia artística y patrimonial en España (cfr. Úbeda de los Cobos, 2001, p. 99 ss.), si bien, como Revuelta nos ilustra con detalle con el ejemplo de Palencia, quedaban aún muchos obstáculos por superar.

\section{DETERIORO DEL PATRIMONIO Y PÉRDIDA DE LA CONCIENCIA ARTÍSTICA: GUERRA DE LA INDEPENDENCIA Y DESAMORTIZACIÓN}

La segunda etapa en los avatares de la conciencia artística es la que abre el siglo XIX, y no duda Revuelta en nombrarla como la "pérdida de la conciencia artística». Dos hechos históricos determinarán esta negativa situación: la guerra de la Independencia y las reformas liberales sobre la Iglesia, especialmente la exclaustración, que produjo el abandono de numerosos 
conventos, la desamortización y la supresión del diezmo. A ello se sumó una falta de aprecio en general de los tesoros artísticos. La responsabilidad de este desprecio, que acabó extinguiendo la anterior conciencia artística ilustrada, se debió a la falta inicial de sensibilidad artística en las clases liberales, que asociaban el patrimonio artístico al poder eclesial. Ese anticlericalismo de origen social y político tuvo así una consecuencia muy nociva en el campo artístico. El panorama no podía ser más adverso para la conservación del patrimonio artístico español. Al parecer el caso palentino no vivió en este sentido ninguna excepción o salvedad. Hubo por causa de la guerra destrozos de edificios históricos, expolios, fundición de piezas de orfebrería, robos múltiples, entre otros de las joyas de la catedral, y robo directo de obras de arte, como el de «la Fontana de Van Eyck», sustraído por el Conde Reille de la Catedral palentina el mes de junio de 1813 (Revuelta, 1999, p. 364, nota 3) ${ }^{2}$.

Si el expolio y el robo fue un deterioro y pérdida directa, quizá la desamortización puede considerarse un daño más a largo plazo o directamente relacionado con el tema que aquí ocupa a Revuelta, que no es meramente el patrimonio artístico palentino, sino la conciencia sobre su valor a lo largo de la historia. Sobre el proceso de desamortización encontramos aportaciones señeras de nuestro historiador, y él mismo hace referencia a un trabajo sobre los avatares de los conventos palentinos en el que ahondaba con detalle en los matices y consecuencias de los procesos de exclaustración y desamortización en la conciencia cultural sobre el patrimonio (cfr. Revuelta, 1992). Revuelta no duda en pedir cuentas históricas a ese desarrollo inicial de un liberalismo en España en exceso ideologizado desde un anticlericalismo intransigente que no supo apreciar o cuidar los tesoros artísticos, y que trajo efectos muy nocivos para la cultura y la misma identidad española. A este respecto aclara que en los decretos de desamortización se preveía la salvación de las obras de arte y de los fondos documentales y archivísticos de los conventos, pero al parecer «la ley anduvo en este caso a la zaga de los hechos consumados» (Revuelta, 1999: 364). Esta situación propició el robo y desmantelamiento de muchos conventos, unido a la vez a un descuido o incapacidad de mantenimiento de numerosas parroquias y ermitas en toda la provincia de Palencia, a lo que se sumaba la situación de penuria generalizada de muchos pueblos. El balance que Revuelta nos hacía en 1999 era desolador: de 32 conventos

2 Revuelta da detallada cuenta de esta obra y su actual ubicación en el Museo del Oberlin College en Ohio, el Allen Memorial Art Museum, por lo que con bastante seguridad se trata de la valiosa copia de la obra La fuente de la vida, atribuida a Jan Van Eyck, ésta actualmente en el Museo del Prado, y que realizó el pintor toledano Gonzalo de Velasco en 1592: cfr. Fransen, 2012, p. 43 ss.; también Armiraglio, 2005, p. 144.s. 
que había activos en 1835, quedaron 23, de los que luego desaparecieron 14 progresivamente, llegando a nuestros días sólo seis conventos conservados en su construcción original y su legado patrimonial artístico ${ }^{3}$.

Hay que tener a la vista todos los factores señalados para comprender cómo al llegar la desamortización, la conciencia artística heredada de la ilustración, que de por sí estaba muy sesgada, con su indolente desprecio del arte barroco y aún del medieval, acabó ahogada y disuelta por un anticlericalismo intransigente, y por eso, los nuevos propietarios de los inmuebles y también con ello de muchas obras de arte de los conventos, no desarrollaron ninguna actitud conservacionista, y Palencia de nuevo no fue una excepción. Revuelta refiere una Real Orden del 15 de febrero de 1842 por la que se autorizaba a vender retablos (muchos de ellos barrocos) para «rascar oro y sacar astillas» (Revuelta, 1999, p. 365). Revuelta entra en detalles realmente sangrantes de lo que ha sido el deterioro y expolio que el mismo pueblo español ha acometido con sus riquezas artísticas. No obstante, el análisis de nuestro historiador conserva en todo momento la contemplación de factores complejos y variados, y así, a esa actitud negligente de autoridades y propietarios, suma la ya mencionada pobreza de los pueblos y también la «actitud fatalista» por parte del clero, unido a su muchas veces deficiente formación artística.

\section{PASOS, AVATARES Y ARTÍFICES DE LA RECUPERACIÓN Y EL «DESCUBRIMIENTO» DE PALENCIA DESDE EL REENCUENTRO DE LA IGLESIA Y EL INTERÉS HISTÓRICO-ARTÍSTICO}

Será en la segunda mitad del siglo XIX cuando vaya emergiendo la recuperación de la conciencia artística en España y concretamente en Palencia; primero desde algunas revistas católicas críticas a las políticas liberales, pero también desde un sentir general por parte de estudiosos e intelectuales que lamentaban la pérdida y deterioro del patrimonio artístico. El romanticismo y su aprecio por el arte medieval fue también un factor en el cambio de perspectiva y apreciación de buena parte del legado artístico en España, país que formó parte del imaginario legendario romántico de viajeros del norte de Europa, y cuyas crónicas fueron conocidas y apreciadas por los propios españoles. A ello añade Revuelta la existencia de un renacer religioso en esa

\footnotetext{
3 Se refiere aquí Revuelta a los conventos como patrimonio artístico, pues cabe decir que en los últimos años se cuentan catorce monasterios palentinos en activo: El norte de Castilla, 2/05/2010. En correspondencia con la Diócesis (11/05/2020) de Palencia se nos informa que hay hasta quince órdenes en total activas en la provincia.
} 
segunda mitad del siglo XIX. Todo ello fue propiciando nuevos y más rigurosos estudios de Historia del arte, publicaciones y revistas que detallaban los monumentos artísticos de modo general y también local. El ateneísmo, la proliferación de sociedades culturales y el excursionismo propiciaron una nueva mirada de interés y estudio de todo el rico legado del pasado. Sin duda aquí habría que nombrar la importante labor de los krausistas y el ambiente cultural que propiciaron, como luego indicaré con más detalle. Todas estas iniciativas surgidas de la sociedad y de los estudiosos e intelectuales tendrán al final, como indica Revuelta, un reflejo paulatino en la administración pública y la legislación, con la creación de comisiones provinciales de monumentos, nombramiento de monumentos nacionales, creación de museos, cuidado de colecciones, e inversión de la administración pública en la restauración del patrimonio arquitectónico y artístico en general.

Pero esta recuperación tuvo sus pasos, no siempre en línea recta. El trabajo de Revuelta se centra a partir de este periodo en su objetivo principal, esto es, en los pasos concretos dados respecto al patrimonio palentino, si bien dependiente de los avatares generales de la política y la sociedad española. Así, a esta primera época de resurgimiento, sucederá una segunda con las contradicciones y crisis al respecto que trajo el sexenio revolucionario, teniendo lugar finalmente la consolidación de la recuperación de la conciencia artística en las últimas décadas del siglo XIX y el comienzo del siglo XX.

Será sin duda la aportación del escritor José María Quadrado (1819-1896) la que dará unos frutos concretos y muy apreciables de esa recuperación de la conciencia artística para el caso de Palencia. Este escritor y viajero mallorquín colaborará en la importante obra colectiva: Recuerdos y bellezas de España (1839-1865), impulsada por el célebre dibujante, pintor y grabador romántico Javier Parcerisa y Boada (Barcelona, 1802-1875), proyecto en el que colaborarían también importantes escritores e historiadores del arte como Pi y Margal o Pedro Madrazo. Quadrado se ocupó entre otras provincias de Palencia ${ }^{4}$ y aportó, junto con Madrazo, rigor histórico y esmero en la descripción de los monumentos, acaso frente a un tono más exaltado y romántico presente en el inicio de este proyecto en las contribuciones del poeta catalán Pedro Piferrer. Revuelta aprecia bien ese rigor y el buen ensamblaje que sabe aportar Quadrado entre el detalle de lo que ve o describe con los acontecimientos y el curso de la historia de las tierras que visita. También es interesante la conjunción que en su escritura se da ya entre el aprecio por el arte y el entorno y el paisaje natural de las tierras palentinas. Nuestro

\footnotetext{
4 Aunque viajó por la provincia en 1853 (Revuelta, 1999, p. 367), su escrito sobre Palencia se publicaba en el Tomo 10 de esta obra dedicado a esta provincia, junto con Valladolid y Zamora (Madrid 1865).
} 
historiador palentino no duda en valorar la contribución de este mallorquín: «Quadrado descubrió Palencia a los españoles y a los mismos palentinos» (Revuelta, 1999, p. 367). Ese lugar frecuentemente velado por otras provincias castellanas quedó en parte resarcido por las detalladas descripciones y valoraciones que este escritor aportó, pudiendo todavía valorar elementos arquitectónicos y artísticos que luego se perderían o deteriorarían, como por ejemplo los capiteles de la sala capitular en el Monasterio de Santa María la Real en Aguilar de Campoo (p. 368 s.). Aquí advertimos como lectores el gran conocimiento y cariño que Revuelta tiene sobre el patrimonio de su tierra; y literalmente goza de alguna manera de esa suerte de viaje en el tiempo que los ojos de los viajeros de antaño nos permiten hacer a través de la escritura, acompañada en ocasiones de bellos grabados y dibujos. Revuelta destaca un pasaje en el que Quadrado deja ver su mayor entusiasmo por el patrimonio artístico de los pueblos que el de la misma ciudad de Palencia ya en esos años. En esos pueblos, advierte Quadrado un esplendor pasado y un acceso casi inmaculado al arte bizantino, como conservado desde siglos. Revuelta destaca la sensibilidad de este escritor para valorar a la vez la pureza de los estilos que se mantenían más en parroquias y emitas fuera de la ciudad, a la vez que su integración con el entorno natural y el mismo paisaje rural. En este autor se une el conocimiento histórico con la sensibilidad religiosa y estética, que le hace apreciar el arte gótico en todo su esplendor y fuerza, así como la profunda dialéctica entre gravedad y ascenso hacia la luz que se da entre este estilo y su precedente, el románico (p. 368), en el ejemplo de la Iglesia de Sta. María la Mayor en Villamuriel del Cerrato, que ciertamente expresa magníficamente ese emerger del estilo gótico. Estos aspectos y esta riqueza en los juicios estéticos, los echaba Revuelta ciertamente en falta en las crónicas dieciochescas sobre los tesoros artísticos palentinos.

En el seguimiento de los juicios de este autor, Revuelta nos lleva a una consideración muy interesante aún hoy candente en torno a la conciencia artística y nuestra relación con el legado de las obras de arte del pasado. Nos indica que Quadrado se lamenta del deterioro y el estado ruinoso de algunos monumentos, y nos detalla Revuelta qué obras de arte y tesoros arqueológicos pudo todavía conocer en su ubicación y estado original en el año del viaje a Palencia (1852) y sin embargo habían sido trasladados ya en el año de la segunda edición de su libro (1885) al Museo Arqueológico Nacional, tales como el sarcófago romano de Husillos o todas las sillerías del coro de las clarisas en Astudillo. Revuelta advierte la queja del mismo Quadrado, sobre este «coleccionismo desmesurado» (Revuelta, 1999, p. 369), dando un elocuente testimonio del mismo viajero mallorquín en una nota a esa segunda edición: «antes de enterrar ningún cadáver no cabe afán ni dispendio excesivo para 
averiguar si aún tiene vida y prolongársela»(Quadrado, 1885, p. 529, nota 1, cit. en Revuelta, 1999, p. 369, nota 9). Esta apreciación ubica la mentalidad de este escritor en una posición muy interesante y actual, que entiende la conservación de las obras e incluso su valor estético en su inserción en su entorno de génesis y nacimiento y en conexión con las dimensiones culturales, religiosas, vitales e históricas que llevaron a la creación de las mismas. Este planteamiento, defendido especialmente por la corriente hermenéutica, que también se separaría de un historicismo anticuario, pues asume que las obras y los estilos se superponen de modo vivo en el tiempo, choca directamente con una abstracción ahistórica de las obras de arte que verá en el museo el lugar ideal y preciso de conservación, estudio y comprensión de la obra, puesta en relación de modo ordenado y enciclopédico con otras corrientes y estilos. Este último modelo coincide con la cultura ilustrada de los museos, que pudo tener y aun hoy tiene, un papel crucial en la conservación y estudio de las obras, y puede incurrir, siguiendo la metáfora usada por Quadrado, en ciertas muertes prematuras de conjuntos artísticos y sobre todo, ya desde el punto de vista de la cuestión de la verdad y sentido vital de la obra y el patrimonio artístico, en una abstracción desconexa y en definitiva distorsionadora de la verdad y sentido de las obras (cfr. Gadamer, 1984, p. 127 ss., 182 ss.). Que Revuelta identifique y valore estas críticas de Quadrado lleva su tratamiento a un nivel mucho más sugerente y profundo que el del mero cuidado material y conservación de las obras, y plantea, desde los ejemplos concretos mencionados de patrimonio palentino y su destino, una revisión de nuestra relación vital con el mismo.

La época de recuperación y progreso de una madura conciencia artística en España quedó a juicio de Revuelta frenada y cuestionada en el periodo isabelino y en los años de la Gloriosa, con el sexenio revolucionario y la proclamación efímera de la primera República. Advierte Revuelta el aprecio por la cultura y las bellas artes que este periodo trajo a través de diversas leyes, que fueron reflejo de los políticos e intelectuales que apoyaron esta etapa. Pero los hechos y acciones de la política cultural hablan en contra de esos planteamientos. Revuelta lamenta la destrucción de la muralla de la ciudad de Palencia, que la despojó de su fisonomía histórica; también se destruyó en esos años el Castillo de Torremormojón ${ }^{5}$. Las decisiones erróneas se

5 Se trata de un ejemplo fundamental de la línea defensiva medieval. Hoy apenas pueden visitarse las ruinas y zócalos de lo que fue el catillo del siglo XV edificado sobre uno medieval anterior y se halla este monumento en la llamada "Lista roja del patrimonio en peligro» de la asociación Hispania Nostra y creada en 2006: cfr. https://es.wikipedia.org/wiki/Castillo_de_Torremormoj\%C3\%B3n; también: García Vega, 1992. 
juntaron con la pobreza y ese anticlericalismo tan arraigado en una parte de la mentalidad progresista en España que produjo un desprecio y negligencia respecto a los bienes culturales del patrimonio eclesiástico y religioso. Esa fiebre coleccionista y museística ya mencionada desde las críticas de Quadrado influyó también en la conservación de la unidad y ubicación de muchas obras y piezas artísticas. Esta tendencia a concentrar las obras en los museos nacionales tenía también mucho de centralismo político. Desde este planteamiento hubo en la política revolucionaria numerosos decretos de incautación de obras, archivos y bibliotecas de iglesias, colegiatas y cabildos (Revuelta, 1999, p. 370). Revuelta indica que había en los años de la revolución un deseo de terminar la desamortización, en este caso en su dimensión no sólo económica y jurídica, sino en su sentido cultural. Se acusaba a la Iglesia de tener numerosos tesoros escondidos y mal cuidados, y se pretendía así devolver al pueblo y secularizar el patrimonio.

Pero ante esta nueva situación de retroceso y en parte expolio y destrozo, no habla ya Revuelta de una nueva pérdida, más bien habría que plantear una modificación de tal conciencia, que sin duda trajo consecuencias desastrosas y de deterioro en la conservación tanto material como espiritual del sentido del patrimonio. De otro lado, señala que ante esta situación no dejó de haber protestas y voces en contra, tanto por parte de autoridades eclesiásticas como por parte de estudiosos e intelectuales. En comparación con la indolencia que se dio ante el deterioro de la desamortización de los años treinta y cuarenta, indica Revuelta que «algo había cambiado» (p. 372). En el contexto palentino destacan así las enérgicas protestas del obispo de Palencia, Juan Lozano, realizadas en torno a 1869. Revuelta vierte un interesante testimonio de sus alegaciones por la vía jurídica, en la que este obispo admite en parte el descuido por parte de la iglesia en algunos casos pero defiende que no ha sido así en otros; e indicando también lo ilógico de tales acusaciones en los casos de despojo y desposesión de las mismas órdenes religiosas y parroquias de sus edificios y bienes. Revuelta nos da detallada cuenta de importantes pérdidas y deterioro del patrimonio ocurridos entre 1871 y 1872 respecto a iglesias y objetos arqueológicos en Husillos, Aguilar de Campoo y Palencia, antes mencionados; y comenta cómo estos hechos fueron denunciados en un escrito significativo de la época titulado «La revolución y las bellas artes» aparecido en la revista La Propaganda Católica en enero de 1872. Este artículo que tenía una intención de denuncia general tomará el ejemplo de los destrozos hechos en la provincia de Palencia, especialmente en Husillos, Aguilar y Carrión como prueba de la responsabilidad política directa de estas acciones, indicando que «con la bandera de la civilización en una mano y la piqueta en la otra» (citado en: Revuelta, 1999, p. 372, n. 13) 
se han acometido destrozos peores que los que hicieron los franceses en la Guerra de la Independencia. El caso del patrimonio palentino y su deterioro jugó así un papel ejemplar en un caso muy significativo en el que la conciencia artística pone en cuestión no sólo la desamortización inicial como un litigio de propiedad entre Iglesia y Estado, sino en una segunda fase como expolio y desatino muy dañino en la conservación y preservación del legado artístico y cultural.

Este cambio en la conciencia artística va permeando definitivamente en las capas populares, despertándose un interés por los patrimonios locales de las diferentes partes de España y sus paisajes. Sin duda la labor de las obras de Parcerisa, Quadrado y Amador de los Ríos fueron sembrando estos frutos. En el caso de Palencia, Revuelta dirige nuestra atención sobre Ricardo Becerro Bengoa (1845-1902), un hombre polifacético como otras figuras del XIX, que reunió su amor a las artes con la actividad política y periodística, además de su sólida formación como científico, obteniendo la plaza de catedrático de Física y Química en Palencia, donde se trasladó desde su Vitoria natal, y donde residirá entre 1870 y 1885, "convirtiéndose en el motor cultural de la ciudad» (RAH, Biogr.), fundando varios periódicos y destacadas instituciones como el Ateneo, el Observatorio y la Sociedad Económica (Revuelta, 1999, p. 372). Entre sus numerosas publicaciones destaca Revuelta El libro de Palencia (1875), del que Revuelta daba referencia de una reciente edición facsímil de 1993 y nos da un aclarador resumen de su contenido y la función histórica que llegó a cumplir para Palencia y la proyección del calor de su patrimonio histórico-artístico. Es un libro, nos dice que compendia datos de todo tipo sobre la provincia: datos económicos, demográficos, sobre industria, minería y agricultura, junto con la historia, el arte y el estado de la enseñanza. El texto también destila la experiencia del viajero y el dibujante que recorrió las tierras y paisajes palentinos en compañía de amigos y aprendió a amar y a sentir esas comarcas. "Es una obra digna de un científico humanista», nos llega a decir como un buen resumen de todo este espíritu (p. 373). Y de ahí percibimos el valor cultural de esta obra y de la función que en definitiva cumplió este personaje. Su obra tenía una gran potencia divulgativa y propagandística, sin desdeñar el rigor y la calidad crítica y detalle de los datos y reflexiones aportadas. Era así una prueba viva de que eran perfectamente compatibles el talente del científico, el del hombre de letras liberal y de ideas progresistas con el respeto del legado histórico y artístico y con la sensibilidad espiritual y estética. Esa actitud se completaba en la obra citada con apuntes críticos y propuestas sobre algunas restauraciones del legado palentino; recomendando así la restauración urgente de la Iglesia de Frómista y censurando otras intervenciones. Estos aportes son interesantes 
pues en esos momentos el patrimonio artístico palentino aún estaba en estado de deterioro y peligro en más de un caso, siendo ya irremediables otras acciones acometidas en el pasado. Al rescate o solución en lo posible de esta situación crítica acudió ese nuevo impulso del humanismo científico al que se refería Revuelta.

Ese es el espíritu de los nuevos intelectuales que se fueron granando en las generaciones de la segunda mitad del siglo XIX en España y que permitieron superar esa triste escisión entre la conciencia artística y el progreso social y político, más allá de las disputas Iglesia-Estado y superando prejuicios anticlericales, y de otro lado sanándose de una actitud insensibles para las realidades locales y rurales. Es verdad que en este último punto ayudó en el caso concreto que describimos la orientación fuerista de Becerro, pero habría que indicar que detrás de toda esta actitud se hallaba sin duda el gran impulso que supuso el krausismo y especialmente la Institución Libre de Enseñanza en la cultura decimonónica española. En efecto, iniciado como una reforma de la Universidad y una incidencia en las políticas educativas, el krausismo fue abriéndose a la sociedad y a la educación en todos sus aspectos y niveles (Vázquez Romero, 2005), propiciando esa característica actitud muy cercana y afín al movimiento ateneísta, propiciadora pionera de una educación más allá de lo académico y especialmente también del excursionismo, que descubre el paisaje, la provincia y el campo desde la metrópoli, que valora lo popular junto a lo más elevado del arte y la literatura. En efecto, desde esta práctica, la Institución Libre de Enseñanza inició en nuestro país el llamando excursionismo por diversos lugares de la geografía peninsular, apelando al estudio del paisaje y el patrimonio en conjunto a implicando esa actividad una renovación y aprendizaje espiritual en sí misma. El geógrafo Rafael Torres Campos (1853-1904), profesor de la ILE, fue el gran artífice de esta actividad, de la mano de Fco. Giner de los Ríos y continuada por M.B. Cossío. El mismo Francisco Giner escribiría en las últimas décadas del XIX para algunas importantes revistas diversos estudios sobre los tesoros artísticos peninsulares que habrían de reunirse bajo el proyecto de una Arqueología artística de la Península, obra que Juan Uña (1838-1909) editaría en 1936 como libro, reuniendo y ordenando esos trabajos ginerianos, frutos muchos de ellos de sus viajes y andanzas por la Península Ibérica, también por localidades de Portugal. Don Francisco no nos llegó a dar cuenta de ninguna localidad palentina, aunque si viajó cerca por tierras de León (Carracedo) (Giner, 1936; Pinilla, 2010); pero sí lo hizo como alumno el propio Juan Uña de la Institución con los profesores Rubio, Sardá y Pedrosa y otros alumnos en los días de fin de año entre 1885 
y 1886 (González Sánchez, 2000, p. 152 ss.) ${ }^{6}$. La detallada descripción de este viaje, conservada en los fondos de la Institución Libre de Enseñanza, combina el relato de viaje con del descubrimiento pedagógico casi virginal de la descripción de Palencia y sus tesoros artísticos, pero también de sus calles, su vida y sus gentes, incluidos los sacristanes y las personas que les mostraban las iglesias y monumentos. José Luis González Sánchez nos da en el citado artículo un testimonio vivo de la actividad institucionista esos días en la ciudad palentina, haciéndonos partícipes casi con los alumnos de asistir y descubrir iglesias como la de San Pablo o la admirada y «esbelta» catedral, de la que Juan Uña dirá que «es un museo arqueológico» (González Sánchez, 2000, p. 165), o admirar el cuadro de la Virgen y San Juan de Andrea del Sarto, en la Iglesia de San Lorenzo, o el San Sebastián de El Greco (pp. 165-166); un testimonio este sin duda que complementaría muy oportunamente la reconstrucción presentada por Revuelta.

\section{CONSOLIDACIÓN DE LA CONCIENCIA Y LA VIDA ARTÍSTICA PALENTINA: ¿RAZONES PARA LA ESPERANZA?}

Revuelta culmina su trayectoria histórica detectando la que denominará la etapa de recuperación de la conciencia artística de modo pleno, que datará a partir de 1875 aproximadamente, con la restauración alfonsina, hasta las primeras décadas del siglo XX. Poco a poco ese acercamiento de las clases intelectuales al aprecio y cuidado del patrimonio culminará en acciones no sólo culturales, sino también políticas y jurídicas que permitirán un cuidado, conservación y conocimiento del patrimonio artístico. Así el decreto del 29 de enero de 1875 entre Iglesia y Estado permitió la devolución a la Iglesia de muchos bienes incautados, propiciando en la medida de lo posible, a pesar del mucho y largo deterioro, cierta unificación y recuperación del patrimonio.

Palencia en este proceso, advierte Revuelta, aún tendrá que esperar, al menos en lo que respecta a hechos de restauración y restitución significativos, pero sí influyó el ambiente y la conciencia artística como tal existente en la ciudad. Aquí la labor de R. Becerro será fundamental, con las diversas instituciones como el Ateneo Palentino y otras antes mencionadas. También destaca Revuelta la presencia del importante pintor palentino José Casado de

6 Seguramente se trataba del Prof. Ricardo Rubio Álvarez de Linera (1865-1935), profesor de botánica en la ILE. 
Alisal (1832-1886), al que precisamente Ricardo Becerro dedicará una completa monografía, publicada en 1886 y reeditada con ocasión del centenario de la muerte de Alisal, a cargo de la Diputación de Palencia. La Escuela de Artes y Oficios de la ciudad fue propiciando la práctica de jóvenes de allí. Cita Revuelta entre otros al escultor Victorio Macho (1887-1966) y se puede decir que se va consolidando una plena conciencia y vida artística palentina, apareciendo escritores y estudiosos que contribuyeron a dar a conocer y difundir con rigor las riquezas artísticas de esta provincia. También en esta recuperación fue clave el buen entendimiento entre la Iglesia y el Estado, surgiendo figuras tanto del clero como profesionales de diversos ámbitos que apoyaron la valoración del arte palentino como un valor en sí mismo que había que conocer y cuidar. En este sentido destaca la figura del médico y antropólogo palentino Francisco Simón Nieto (1856-1920), de talante liberal y con numerosas publicaciones sobre el legado artístico de Palencia y de otros lugares castellanos (Sánchez Rico, 20207); y por otra parte el eclesiástico Enrique Almaraz Santos (1847-1922), bajo cuyo ejercicio como obispo de la ciudad (1893-1903) se propició la conservación y el estudio y defensa del arte palentino.

En estos años tiene una actividad efectiva la Comisión de Monumentos de Palencia, constituida el 7 de enero de 1894 (Álvarez Sanchís, Cardito, 2000, p. 196) y llevará a cabo algunas restauraciones importantes del patrimonio artístico. La figura de Simón Nieto, presente en esta comisión desde su fundación, fue clave en este sentido, pues a los numerosos estudios y su importante labor divulgativa y difusión del valor del arte palentino fuera de la provincia, contribuyeron de modo muy eficaz sus informes sobre el estado de muchas iglesias y monumentos en situación deteriorada o ruinosa. Entre otros destaca Revuelta «el precioso y convincente informe sobre la ruina que padece San Martín de Frómista» (Revuelta, 1999, p. 376); informe que se acompañó de las gestiones pertinentes de su parte para la recuperación de esta importante iglesia. Su obra Los antiguos campos góticos (1894), de la que Revuelta nos cita una recepción entusiasta por parte del mismo Quadrado, será la primera monografía sobre los tesoros artísticos de la comarca de Tierra de Campos y gozará hasta nuestros días de varias ediciones y revisiones, convirtiéndose en un libro clásico y de referencia (cfr. Revuelta, 1999, p. 376 s.; Simón Nieto, 2006). Revuelta señala esta obra como la que más ha contribuido a «despertar la conciencia artística de Palencia».

7 El pasado 16 de febrero de este año (2020) se cumplía precisamente el centenario del fallecimiento de este insigne «humanista palentino» (Sánchez Rico, 2000). 
Al estudio de Simón Nieto se sumaron un buen número de escritos y artículos que en sintonía con el apoyo eclesiástico consolidaron la conciencia artística palentina. El obispo Alcaraz, escribiendo en 1900 sobre la Iglesia de San Andrés, llega a considerar su diócesis como un «inmenso museo arqueológico» (cit por Revuelta, p. 378). Esta expresión nos da pie a ver en ella realizada esa conciencia artística madura que lejos de desencajar y "coleccionar» las obras en muesos, admira estas en su ubicación y vida original. El «museo», esto es, lo digno de verse y visitar, está ya en el entorno arquitectónico, artístico y vital que forman el paisaje y la geografía imbricada con las gentes y su historia. A la actividad de Almaraz, se sumarán otros eclesiásticos ilustres como Matías Vielva o Antonio Álvarez Reyero. Desde el punto de vista de su gestión, numerosos monumentos fueron restaurados y se invirtió en su mantenimiento, e incorporó la asignatura de Arqueología en los estudios del seminario diocesano. La vida religiosa católica tomo un nuevo auge y aunque indica Revuelta que este movimiento tenía un sentido de reacción contra la desamortización y el anticlericalismo decimonónico, no deja de advertir el aprecio y valoración que este resurgimiento acompañó respecto a las ermitas, iglesias y obras artísticas religiosas por parte del pueblo, propiciando que todo ese patrimonio, por decirlo así, recuperase una vida en muchas ocasiones aletargada o velada. A las numerosas peregrinaciones por la provincia que este movimiento ocasionó, se sumó la importante actividad civil de la Sociedad Castellana de Excursiones, que se fundaría en Valladolid en 1903. Aunque menos multitudinaria y popular, esta Sociedad aglutinó a numerosos estudiosos y entusiastas, muchos de ellos ya nombrados (Alcaraz y Simón Nieto entre otros), y su Boletín dio testimonio de la relevancia cultural de un amplio patrimonio en toda la provincia palentina. Todas estas actividades, y esta Sociedad de modo notable, propiciaron la declaración de monumentos nacionales de numerosos edificios y emplazamientos de la provincia (Frómista y Baños en primer lugar), así como efectivas y cuidadas restauraciones. Para conseguirlo había no sólo que preparar informes del estado de ruina y la necesidad de reparación, sino exponer los méritos y valor de cada edificio, produciéndose así un periodo de íntima colaboración entre el estudio y la acción de cuidado y conservación, acaso una de las claves esenciales que mantienen viva la conciencia artística de una región y una comarca. Para ello es necesario combinar el aprecio y conocimiento de lo local con una formación universal amplia, que permita valorar en su justa medida los tesoros y legados artísticos de cada ciudad y cada provincia. Palencia pudo alcanzar esa situación casi ideal en ese convulso cambio de siglo en España. Revuelta localiza concentrado este espíritu en el acto de reapertura de la 
Iglesia de San Martín de Frómista el 11 de noviembre de 1904, tras ocho años de trabajos de restauración. Al parecer fue una celebración religiosa multitudinaria en la que hubo también alocuciones de eclesiásticos y estudiosos, subrayando la íntima colaboración entre el arte y la religión, las relaciones entre el arte y la ciencia, o, en la intervención de Sergio Aparicio, miembro de la comisión de monumentos desde su fundación, del «sentido espiritual de la restauración»(Revuelta, 1999, p. 384).

A pesar de tener que datar sin escrúpulo numerosas aberraciones y descuidos respecto al cuidado del patrimonio y dar cuenta de una casi total extinción de la conciencia artística en España y por ende en esa tantas veces olvidada Palencia, Revuelta parece concluir su recorrido con esperanza, y reconociendo una recuperación plena de la conciencia artística palentina. Desde ese inicio del siglo XX, donde nuestro historiador termina su reconstrucción, sabemos que ocurrirán sucesos históricos cruciales y virulentos para España y por ende en relación con su patrimonio; baste citar la Guerra Civil, pero como indica Revuelta, las semillas para esa conciencia artística y valoración del patrimonio habían sido ya plantadas. En el año 1999, justo cuando se publicaba este estudio, se celebraba una nueva edición de Las Edades del Hombre en Palencia, con el título de "Memorias y esplendores», evento al que Revuelta hace referencia al principio de su escrito y que califica como «una ocasión preciosa para dar a conocer las riquezas artísticas de toda la Provincia»(Revuelta, 1999, p. 359). Aunque no es objeto de su estudio, pero sin duda que esta asociación de carácter religioso que tanto ha impulsado el conocimiento del arte y el patrimonio castellano y leonés en los últimos años, desde su fundación en Valladolid en 1988, es una buena muestra de esa conciencia artística viva en la que se aúna lo espiritual, lo religioso, lo artístico y lo histórico.

Revuelta acaba su artículo con palabras de esperanza y optimismo, y su mismo trabajo cuidadoso y minucioso de estudio y relato de los hechos como gran historiador de estas pequeñas pero grandes hazañas que paisanos suyos, nativos y de adopción, llevaron a cabo en años pasados para recuperar la conciencia artística y con ello la valoración y estudio del legado humano y espiritual de las tierras palentinas, es una muestra más de esa actitud laboriosa unida al afán y al amor por el objeto tratado, y no otra cosa significa «estudio» en su acepción griega; algo que Manuel Revuelta ejerció sin paliativos y nos dejó en sus obras como testimonio vivo y ejemplar. 


\section{REFERENCIAS}

\section{Escritos de Manuel Revuelta}

Revuelta, M. (1992). Orígenes, ocaso y renovación de los conventos palentinos. Publicaciones de la Institución Tello Téllez de Meneses, núm. 63, 47-84.

Revuelta, M., (1996). Iglesia, religiosidad tradicional y disidencias. En P. García Colmenarejo, J. Moreno Lázaro, J.L. Sánchez García (coord.) Historia de Palencia: Siglos XIX y XX, Palencia: El Norte de Castilla, 289-300.

Revuelta, M. (1999). La recuperación artística en Palencia. Publicaciones de la Institución Tello Téllez de Meneses, núm. 70, 359-384.

\section{OTRAS REFERENCIAS}

Álvarez Sanchís, J.; Cardito, L. M. ${ }^{\text {a }}$. Comisión de Antigüedades de la Real Academia de la Historia. Castilla y León. Catálogo e índices. Madrid: Real Academia de la Historia.

Armiraglio, F. (2005). Van Eyck. Presentación de Joaquín Yarza Luances. Madrid: Los Grandes Genios del Arte. Biblioteca el Mundo.

El Norte de Castilla 2/05/2010 «220 religiosas residen en 14 monasterios palentinos».

Fransen, B. (2012). Van Eyck y España. Un viaje y una obra. Anales de Historia del Arte 39, Vol. 22, Núm. Especial. 39-58.

Gadamer, H-G. (1984). Verdad y método. Salamanca: Sígueme.

García Vega, B. (1992). Torremormojón. Iglesia de Santa María del Castillo. Palencia: Diputación de Palencia.

Giner de los Ríos, F. (1936). Arqueología artística de la Península. Obras Completas de Francisco Giner de los Ríos. Tomo XX. Madrid: Espasa-Calpe.

González Sánchez, I. (2000). Una excursión de alumnos de la Institución Libre de Enseñanza a la ciudad de Palencia en 1885. Tabanque. Revista de Pedagogía. Núm. 15. 151-170.

Pinilla, R. (2010). La «Arqueología artística de la Península» de Francisco Giner de los Ríos y la contribución krausoinstitucionista a una historiografía artística del arte. En: J.L. Mora, R.E. Mandado, G. Gordo, M. Nogueroles (eds.), La Filosofía y las lenguas de la Península Ibérica, Madrid: Fund I. Larramendi, Asoc. Hispanismo Filosófico et. al. 209-228.

Quadrado, J. M ${ }^{\mathrm{a}}$. (1885). España, sus monumentos y artes - su naturaleza e historia. Valladolid, Palencia y Zamora. Barcelona: Talleres de Daniel Cortezo.

Real Academia de la Historia. Biografías enlace: dbe.rah.es.

Sánchez Rico, R. Un siglo sin el humanista palentino Francisco Simón Nieto. El Norte de Castilla, Domingo, 16 de febrero de 2020. 